\title{
Evaluation of Self-Reported Agricultural Tasks, Safety Concerns, and Health and Safety Behaviors of Young Adults in U.S. Collegiate Agricultural Programs
}

\author{
Jenna L. Gibbs ${ }^{1, *} \mathbb{D}$, Kayla Walls ${ }^{1,2}$, Carolyn E. Sheridan ${ }^{1}$, David Sullivan ${ }^{1}$, Marsha Cheyney ${ }^{3}$, Brandi Janssen ${ }^{3}$ \\ and Diane S. Rohlman ${ }^{3}$ \\ 1 Ag Health and Safety Alliance ${ }^{\mathrm{TM}}$, Greenville, IA 51343, USA; kwalls@iastate.edu (K.W.); \\ carolyn@aghealthandsafety.com (C.E.S.); dsullivan@aghealthandsafety.com (D.S.) \\ 2 Department of Agricultural and Biosystems Engineering, Iowa State University, Ames, IA 50011, USA \\ 3 Department of Occupational and Environmental Health, University of Iowa, Iowa City, IA 52242, USA; \\ marsha-cheyney@uiowa.edu (M.C.); brandi-janssen@uiowa.edu (B.J.); diane-rohlman@uiowa.edu (D.S.R.) \\ * Correspondence: jennagibbs@aghealthandsafety.com
}

\section{check for} updates

Citation: Gibbs, J.L.; Walls, K.; Sheridan, C.E.; Sullivan, D.; Cheyney, M.; Janssen, B.; Rohlman, D.S. Evaluation of Self-Reported Agricultural Tasks, Safety Concerns, and Health and Safety Behaviors of Young Adults in U.S. Collegiate Agricultural Programs. Safety 2021, 7, 44. https://doi.org/10.3390/ safety7020044

Academic Editor: John McNamara

Received: 4 March 2021

Accepted: 31 May 2021

Published: 3 June 2021

Publisher's Note: MDPI stays neutral with regard to jurisdictional claims in published maps and institutional affiliations.

Copyright: (c) 2021 by the authors. Licensee MDPI, Basel, Switzerland. This article is an open access article distributed under the terms and conditions of the Creative Commons Attribution (CC BY) license (https:/ / creativecommons.org/licenses/by/ $4.0 /)$.

\begin{abstract}
Young adults enrolled in collegiate agricultural programs are a critical audience for agricultural health and safety training. Understanding the farm tasks that young adults engage in is necessary for tailoring health and safety education. The project analyzed evaluation survey responses from the Gear Up for Ag Health and Safety ${ }^{\mathrm{TM}}$ program, including reported agricultural tasks, safety concerns, frequency of discussing health and safety concerns with healthcare providers, safety behaviors, and future career plans. The most common tasks reported included operation of machinery and grain-handling. Most participants intended to work on a family-owned agricultural operation or for an agribusiness/cooperative following graduation. Reported safety behaviors (hearing protection, eye protection, and sunscreen use when performing outdoor tasks) differed by gender and education type. Male community college and university participants reported higher rates of "near-misses" and crashes when operating equipment on the roadway. One-third of participants reported discussing agricultural health and safety issues with their medical provider, while $72 \%$ were concerned about the health and safety of their family and co-workers in agriculture. These findings provide guidance for better development of agricultural health and safety programs addressing this population-future trainings should be uniquely tailored, accounting for gender and educational differences.
\end{abstract}

Keywords: agriculture; eye protection; farm youth; occupational health; outreach; hearing conservation; roadway; safety culture; sun safety; young adults

\section{Introduction}

The National Institute for Occupational Safety and Health (NIOSH) has acknowledged that farming is one of the most dangerous professions in the United States (USA) [1]. Each year, more than 2 million youth aged 20 years and younger are exposed to farmrelated safety hazards [2,3]. Most agricultural health and safety training programs for younger populations are specifically designed for children in agriculture (teenage years and younger), such as the Progressive Agriculture Safety Days program [4,5]. However, many collegiate-age adults (ages 18-25) are also actively involved in agriculture. The number of graduates from collegiate agricultural programs in the workforce is growing at a rate of $3.7 \%$, from 2017 to 2019 [6,7]. In the past few decades, higher rates of agricultural operators are pursuing college degrees ( 25\%), typically baccalaureate or associate degrees in agricultural programs [8]. This is on trend with the increasing rates of collegiate education among general rural populations [9]. Higher education levels among farmers have been found to positively influence farm efficiency, use of precision agriculture, higher farm incomes, and larger farm size [10-13]. 
From the perspective of agricultural health and safety professionals, it is important to train young adults since they will be the next generation of agricultural workers. Collegeeducated individuals will play a key role in replacing an aging agricultural workforce, as the most recent USDA census identified the average age of farm operators to be 59 years old [14]. In addition, young adults have the ability to impact safety culture through interactions with their parents, grandparents, and other co-workers (including other family members). They may also be the primary supervisor of children on the farm, such as younger siblings [15]. The Ag Health and Safety Alliance ${ }^{\mathrm{TM}}$ (AHSA) is a nonprofit organization focused on training young adults in collegiate agricultural programs through a program called Gear Up for Ag Health and Safety ${ }^{\mathrm{TM}}$ (Gear Up for Ag ${ }^{\mathrm{TM}}$ ). This program involves collaboration with host institutions and involves interactive lectures, graphics, videos, live polling, problemsolving, storytelling, and hands-on demonstrations of safety equipment by professionals.

While other studies have analyzed personal protective equipment use and work behaviors among young agricultural populations (14-19 years old) [15,16], few studies have sought to analyze young adults enrolled in collegiate agricultural programs. The aim of this project is to utilize Gear Up for Ag ${ }^{\mathrm{TM}}$ program pre- and post-surveys to gather information about the nature of work among college-age young adults enrolled in agricultural degree programs in the upper Midwest region of the USA. This includes demographics (e.g., gender, age), types of farm tasks performed, frequency of discussing health and safety concerns with healthcare providers, and concerns about the safety of other workers (family members, co-workers, peers). Some self-reported health and safety behaviors related to agricultural work and roadway safety were also examined. We examined the potential differences between age, gender, and type of educational institution (university or community college). As the first study of its kind, this information will provide guidance for better development of agricultural health and safety training programs for this population.

\section{Methods}

In 2017, the Gear Up for $\mathrm{Ag}^{\mathrm{TM}}$ program was developed to train young adults in collegiate agricultural programs on a range of agricultural health and safety topics using evidence-based information. The training program ranges from 2 to $5 \mathrm{~h}$ in length, and most participants are 18-25 years old. To evaluate the program, AHSA uses a pre- and postsurvey model developed based on Kirkpatrick's Four-Level Training Evaluation Model [17]. This survey data is collected for the ongoing evaluation and improvement process of the Gear Up for $\mathrm{Ag}^{\mathrm{TM}}$ program and is not generalizable to individuals outside of the program. Both the pre- and post-surveys were developed in 2017 with academic partners and farmers. The common agricultural tasks listed on the survey were identified through focus groups conducted previously with agricultural producers (crop and livestock). After several iterations, the final surveys were pilot-tested among 161 students. Prior to data analysis, the University of Iowa IRB reviewed this outreach evaluation project in 2020 and determined that the project was non-HSR research since no identifying information was collected and it was an evaluation of community education programs for a specific setting (see IRB information at the end of this publication). For this project, the pre-survey was administered two to three weeks prior to program delivery, and the post-survey was administered two to three months following the program. Both surveys collected demographic information such as gender, education type, age, and agricultural career plans following graduation. Participant surveys for this project were collected in the Midwestern U.S. from participants in Illinois, Iowa, Missouri, and Minnesota. The presurvey collected information about self-reported farm activities and safety behaviors performed in the last 12 months; reported discussion of agricultural health and safety prevention methods with a healthcare provider; and concerns for health of family members, co-workers, and friends who work in agriculture. These items were grouped into categories called Machinery Operation, Grain-Related Tasks, Livestock Tasks, Other, and None. In addition, AHSA staff partnered with colleagues at two NIOSH-Funded Centers for Agricultural Safety and Health (Great Plains Center for Agricultural Health and the Central 
States Center for Agricultural Safety and Health) [18], to develop and include survey questions about reported safety behaviors. These safety behavior questions included the use of eye protection when performing tasks such as grinding, cutting, or mowing; use of sunscreen while performing outdoor agricultural tasks; use of hearing protection devices when exposed to loud noises; and "near-misses" and crashes experienced while operating farm equipment on roadways.

Pre-survey responses are used to customize the training to specific needs of the participants, informing the evidence-based curriculum to make the program more relatable and meaningful. For example, if a large number of participants at a particular host institution reported "never" wearing sunscreen, additional time may be devoted to this specific topic during the training delivery. Likewise, if a large proportion of reported "never" or "sometimes" wearing hearing protection devices when exposed to loud noises, extra time could be devoted to the discussion of hearing conservation and how participants select hearing protection for appropriate tasks. Participants could share the conditions under which they warrant wearing hearing protection versus when they refuse to wear the protection, which, in turn, could improve future training programs.

The post-survey collected information on self-reported changes in agricultural health and safety awareness, agricultural career plans following graduation, and intention to share new knowledge with others working in agriculture (family, co-workers, and friends). The post-survey also collected information about intended use of personal protective equipment and purchase of additional protective equipment. To gather further information about potential changes in behavior after the training, AHSA educational staff collected qualitative input by asking participants (after class or through email) about their "biggest take-away or lesson learned" during the training. After the training was completed, detailed summaries of survey responses were provided to the host institution (university or community college), with the intent to use the results to foster health and safety discussions and mentorship throughout the academic year.

\section{Data Analysis}

From 2018 to 2020, there were 736 participant responses for the pre-survey and 201 responses for the post-survey. This low post-survey response rate $(25 \%)$ is typical in other studies on farmer-populations [19]. It is known that farmer-populations are more likely to answer a short survey that is received during the off-season and offers monetary compensation [20]. While this post-survey was relatively short (6-8 min in length), monetary compensation was not offered, and the survey was always administered two to three months after the training program. The low post-survey response rate is acknowledged as a limitation in this study. Demographics of pre- and post-survey participants are presented in Table 1.

Proportions were calculated for pre-survey responses about types of farm tasks performed, discussion of agricultural health and safety concerns with healthcare providers (yes/no), and concern for the safety of other agricultural workers (family, co-workers, and friends). Proportions were also calculated for pre-survey responses on self-reported safety behaviors, including frequency of sunscreen use (always/sometimes/never), frequency of hearing protection device use (always/sometimes/never), frequency of eye protection use (always/sometimes/never), and reported "near-miss" incidents (yes/no) or crashes (yes/no) on the roadway while operating farm equipment. Proportions were calculated for post-survey responses for self-reported agricultural career plans; change in health and safety awareness; and intention to share health and safety knowledge with family, co-workers, and friends. All proportions were compared between groups using a two proportions $\mathrm{Z}$ test for gender, education type (university or community college), and age. A power calculation was performed to check for adequate sample size [21]. The two-sample Z-test is a common method used to evaluate proportional differences between two groups of interest [22]. Age was grouped into two categories based on the median age of pre- and post-survey participants ( $\leq 20$ years and $\geq 21$ years). Further analysis determined that age 
did not influence response outcome, and therefore, proportional responses are presented by gender and education type. Statistical analyses were performed using R Studio@ Version 1.3.1093 (2020).

Table 1. Demographics of Pre- and Post-Survey Participants ( $N=790$ pre-survey; $N=201$ post survey).

\begin{tabular}{ccc}
\hline & Pre-Survey $N$ (\%) & Post-Survey $N$ (\%) \\
\hline Education Type & & \\
\hline Community College (CC) & $406(55.1 \%)$ & $87(43.3 \%)$ \\
\hline University (U) & $329(44.7 \%)$ & $114(56.7 \%)$ \\
\hline Missing ${ }^{1}$ & $1(0.2 \%)$ & N/A \\
\hline Gender & & $67(39.4 \%)$ \\
\hline Females & $130(17.7 \%)$ & $103(60.6 \%)$ \\
\hline Males & $535(72.7 \%)$ & N/A \\
\hline Missing ${ }^{1}$ & $71(9.6 \%)$ & $103(51.3)$ \\
\hline Age & & $98(48.7)$ \\
\hline 20 years old or less & $412(52.1 \%)$ & N/A \\
\hline 21 to 34 years old & $378(47.9 \%)$ & \\
\hline & $0(0.0 \%)$ & \\
\hline
\end{tabular}

${ }^{1}$ Missing = The question was left blank on the survey.

\section{Results}

Demographic characteristics of pre- and post-survey participants are presented in Table 1 . In the pre-survey, $55 \%$ of participants were enrolled in a community college agriculture associate degree program, and $45 \%$ were enrolled in a university baccalaureate program. Approximately $18 \%$ of pre-survey participants were female, and $73 \%$ were male. In the post-survey, $43 \%$ of participants were enrolled in a community college agriculture associate degree program, and $57 \%$ were enrolled in a university baccalaureate program. Approximately $39 \%$ of post-survey participants were female, and $61 \%$ were male.

\subsection{Pre-Survey}

In the pre-survey, $72 \%$ of participants stated they were concerned about the health and safety of family, co-workers, and friends in agriculture. One-third (33\%) stated that they have previously discussed health and safety concerns related to agricultural work with a health care provider in the past. There were no differences observed by age, gender, or education in these responses.

Figure 1 shows the complete list of farm tasks performed and the proportion of participants reporting each task. Overall, the most common tasks reported included operation of machinery (such as a tractor, ATV, or harvesting equipment) and grain-related tasks (such as unloading grain and cleaning grain storage areas). There were statistically significant differences in reporting specific tasks among gender and education type. The most common farm-related tasks reported by males enrolled in community colleges included operation of tractors $(89 \%)$ and ATVs $(84 \%)$, unloading grain $(76 \%)$, and cleaning grain storage $(71 \%)$. Similar trends were observed among males enrolled at universities, whose reported tasks included operating tractors (73\%) and ATVs (66\%), unloading grain (58\%), and working large animals (e.g., hogs/cattle) (67\%). In comparison, the most common tasks reported by females enrolled in community colleges included working with large animals (59\%), operating ATVs (62\%), cleaning animal pens/housing (61\%), and operating tractors (73\%). The most common tasks reported by females enrolled in universities included working large animals (52\%), operating tractors (46\%), operating ATVs ( $46 \%$ ), and cleaning animal pens/housing (46\%). Two-proportion Z-tests revealed significant differences in frequen- 
cies of reported tasks between university and community college participants and male and female participants. Larger proportions of community college participants reported operating tractors and ATVs, cleaning grain storage and animal housing, working with hay, working and feeding livestock, working with agrochemicals, and welding. A larger proportion of male participants reported operating tractors, hauling and unloading grain, mixing feed, feeding animals, handling agrochemicals, and welding. As compared to males, a larger proportion of female participants reported working with poultry.

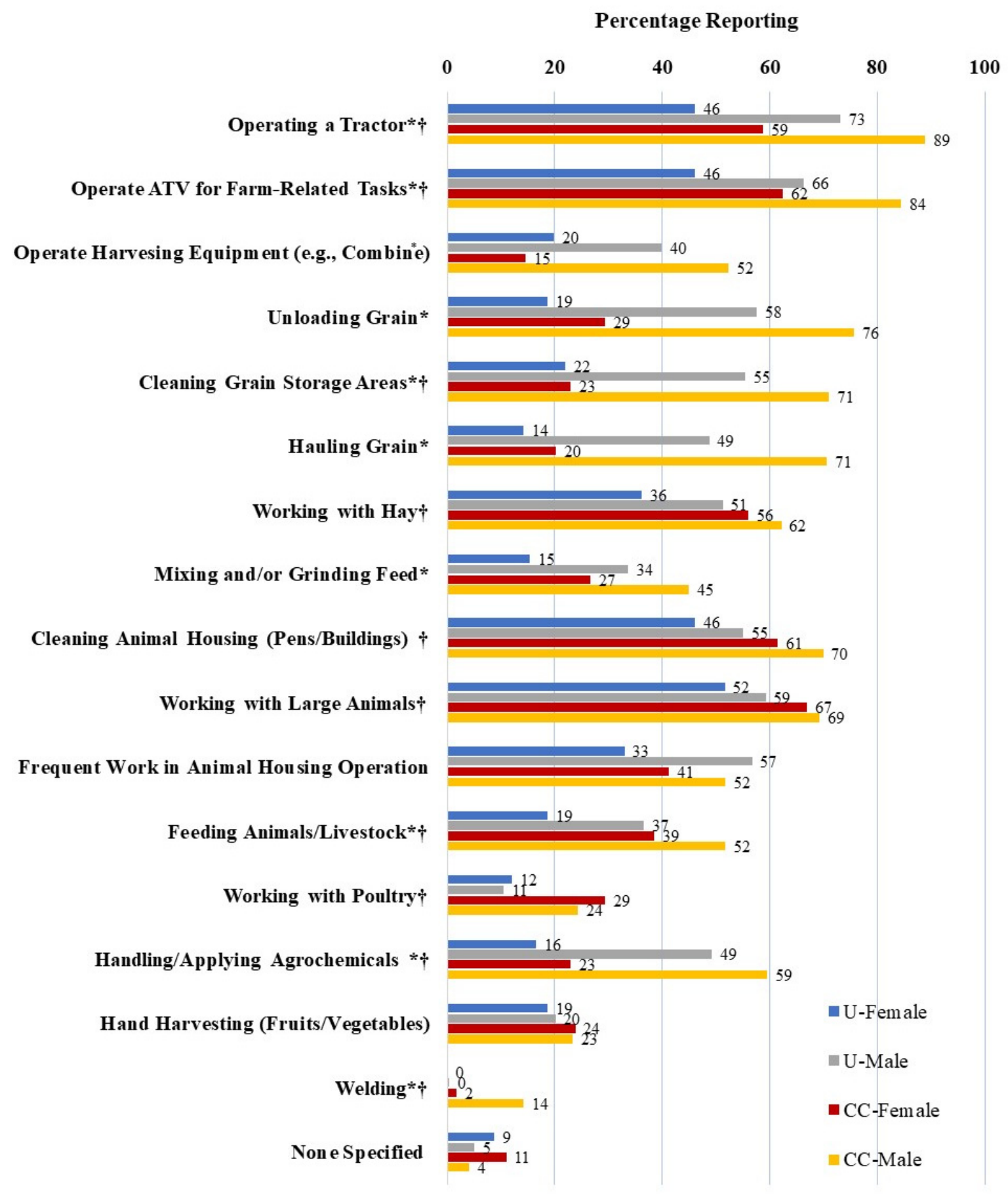

Figure 1. Proportion of participants reporting farm tasks performed in the previous 12 months. Note: Female $=$ University female; U-Male = University male; CC-Female = Community College Female; CC-Male = Community College Male. ${ }^{*}$ Indicates differences between male and female responses, using a 2 proportions Z-test $(p \leq 0.05)$; † Indicates differences between university and community college responses, using a 2 proportions Z-test $(p \leq 0.05)$. 
Figure 2a-c show the reported frequency of safety behaviors by gender and education type, such as wearing hearing protection devices when exposed to loud noises; eye protection when performing tasks such as cutting, grinding, and mowing; and sunscreen use when performing outdoor tasks. For these behaviors, most participants reported "sometimes" (61-72\% for hearing protection device, $54-58 \%$ for eye protection, and $58-77 \%$ for sunscreen use). There were some significant differences among education type and gender. Participants enrolled in universities were more likely to report "always" wearing hearing protection devices (19\% and $14 \%$ for females and males, respectively) when working in noisy environments. Participants enrolled in universities were also less likely to report "never" wearing hearing protection (9\% and 19\% for females and males, respectively) compared to participants enrolled in community colleges $(29 \%$ and $19 \%$ for females and males, respectively). Participants enrolled in universities were more likely to report "always" wearing eye protection ( $31 \%$ and $26 \%$ for females and males, respectively) when performing tasks such as grinding, cutting, or mowing. Participants enrolled in universities were also less likely to report "never" wearing eye protection $(6 \%$ and $8 \%$ for females and males, respectively) compared to participants enrolled in community colleges $(15 \%$ and $13 \%$ for females and males, respectively). Female participants were more likely to report "always" wearing sunscreen when working outdoors (13\% for females enrolled in both community colleges and universities) when compared to males (9\% and $6 \%$ for males enrolled in community colleges and universities, respectively). Females were less likely to report "never" wearing sunscreen $(10 \%$ and $21 \%$ for females enrolled in community colleges and universities, respectively) when compared to males (27\% and $36 \%$ for males enrolled in community colleges and universities, respectively).

Figure 3 shows the reported "near-miss" incidents and crashes experienced when operating farm equipment on roadways, by gender and education type. Overall, there were 90 crashes and 101 "near-misses" reported. Male community college and university participants reported being in a crash at significantly higher rates $(9 \%$ and $11 \%$, respectively) than female participants ( $3 \%$ for both groups). Male community college and university participants also reported being in "near-miss" incidents at higher rates $(10 \%$ and $12 \%$, respectively) than female community college and university participants (4\% and $3 \%$, respectively). This was not surprising, given that approximately three-quarters of male participants reported operating tractors and half reported operating harvesting equipment (such as combines), which was significantly more than reported by female participants (Figure 1). 


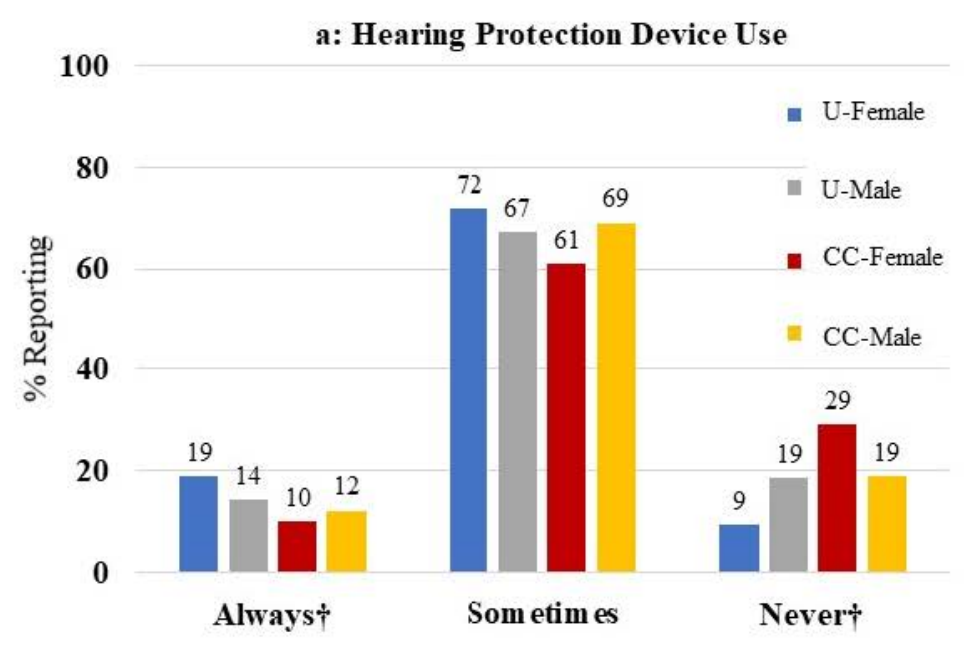

\section{0 \\ b: Eye Protection Use}

\section{0}

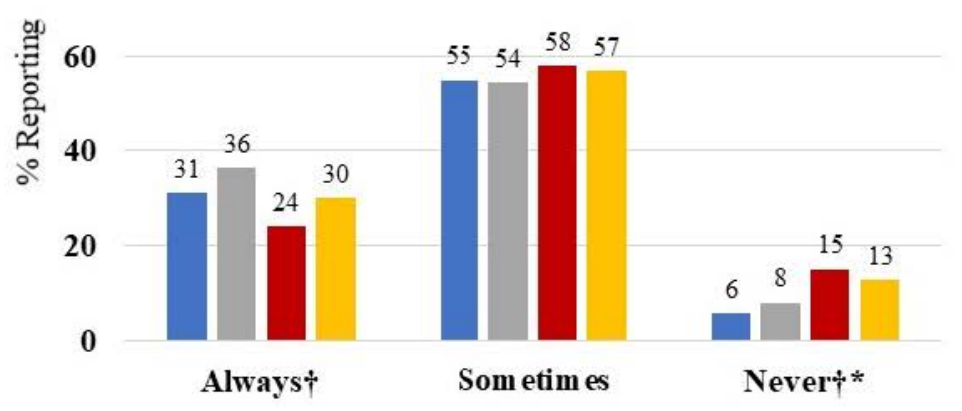

\section{c: Sunscreen Use}

100

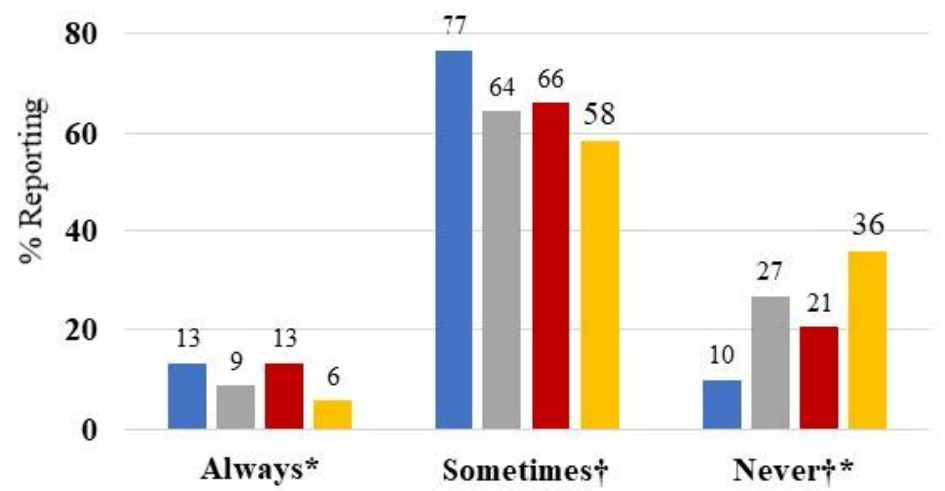

Figure 2. Proportion of participants reporting safety behaviors such as hearing protection device, eye protection, and sunscreen use when performing agricultural tasks. Note: U-Female = University female; U-Male = University male; CC-Female = Community College Female; CC-Male = Community College Male. ${ }^{*}$ Indicates differences between male and female responses, using a 2 proportions Z-test $(p \leq 0.05) ;+$ Indicates differences between university and community college responses, using a 2 proportions Z-test $(p \leq 0.05)$. 
100
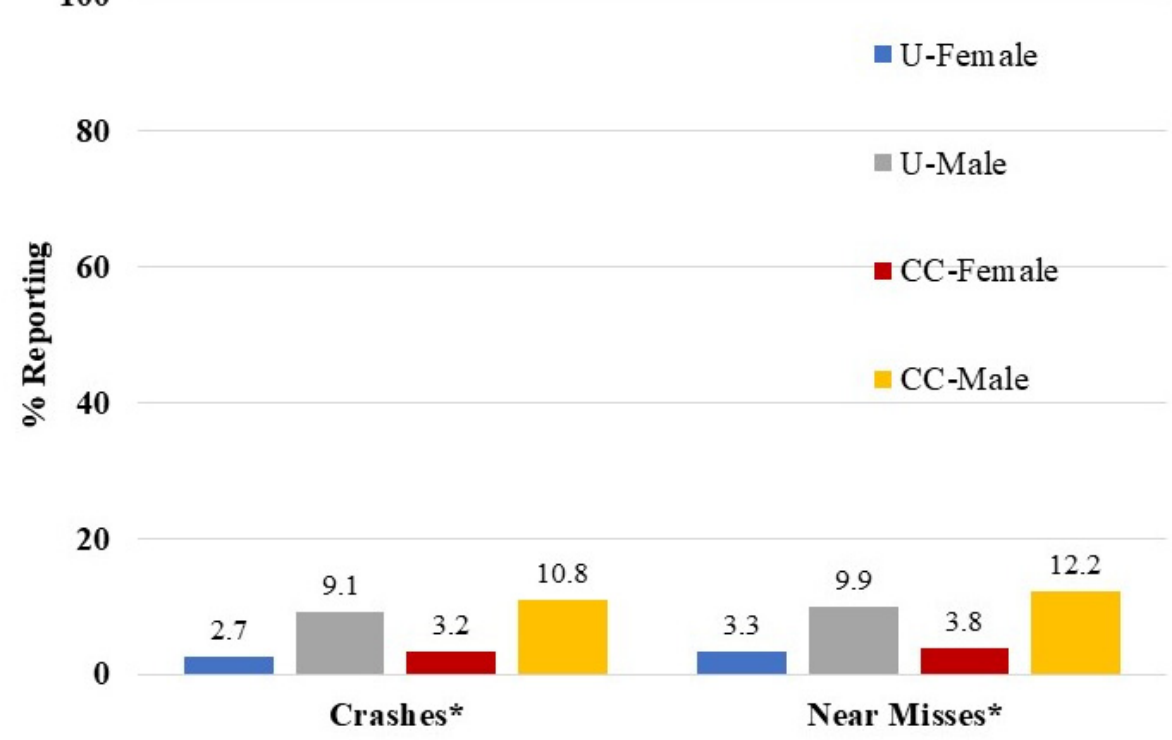

Figure 3. Proportion of participants reporting "near-miss" incidents and crashes while operating farm equipment on roadways. Note: U-Female = University female; U-Male = University male; CC-Female = Community College Female; CC-Male $=$ Community College Male. ${ }^{*}$ Indicates differences between male and female responses, using a 2 proportions Z-test ( $p \leq 0.05)$.

\subsection{Post-Survey}

In the post-survey, participants were asked questions about plans for their future career in agriculture following graduation. Figure 4 shows a list of agricultural careers and the proportion of student participants pursing each career. The most common agricultural careers being pursued were working on a family-owned agricultural operation or for an agricultural business or cooperative. There were differences observed between education level and gender-male participants were more likely to report future work on familyowned agricultural operations ( $60 \%$ and $42 \%$ for males enrolled in community colleges and universities, respectively). Female participants were more likely to report future work for agricultural businesses or cooperatives ( $46 \%$ and $35 \%$ for females enrolled in community colleges and universities, respectively). University participants (males and females) were more likely to report working in consulting, ag health/safety, government or financial services, or undecided.

Following the training, $87 \%$ of participants indicated that they intended to share the information with their family members, co-workers, and friends. In addition, $89 \%$ of participants reported that they were more aware of the health and safety issues discussed at the training. These topics included sun protection, hearing protection, and safe operation of farm equipment on roadways.

It should be noted that participants were also given two types of hearing protection devices (e.g., E-A-R Push-Ins Round Foam Earplugs and the Peltor Next Triflange ReUsable Earplugs) and one pair of safety glasses (e.g., SecureFit ${ }^{\mathrm{TM}}$ Anti-fog safety glasses $\left(3 \mathrm{M}^{\mathrm{TM}}\right.$, St. Paul, MN, USA)) as part of a kit containing personal protective equipment. In the post-survey, $89 \%$ of participants stated that they were motivated to wear hearing protection devices more frequently when exposed to loud noises, and $91 \%$ stated they were motivated to wear eye protection more often. For example, one male participant (in Iowa) stated, "I didn't wear any hearing protection before this training, and now I am going to go buy some." A female participant (in Iowa) stated, "One of my biggest takeaways from the training was that I didn't realize that the types of particles that can do damage to your eyes when cutting metal may not be visible-I need to think about wearing safety glasses 
more often." In the post survey, participants were asked if they had purchased additional hearing protection devices since the date of the training. Overall, $16 \%$ of participants purchased hearing protection devices and 30\% purchased safety glasses in addition to the types provided in the PPE kit. There were no significant differences observed by education type, gender, or age in post-survey responses. Although the training seems to have been effective, these response outcomes may have been biased by low post-survey response rates.

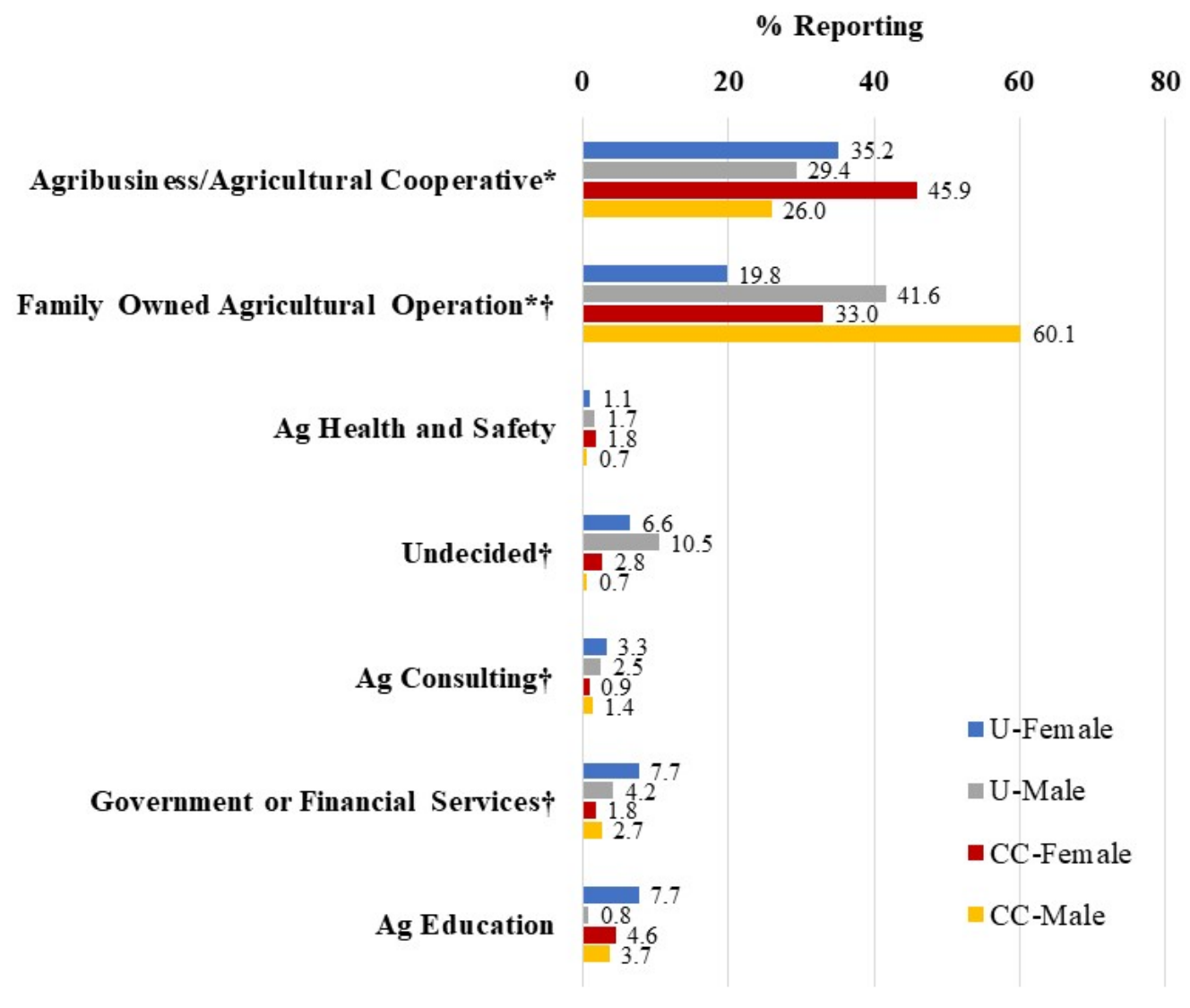

Figure 4. Proportion of participants reporting agricultural career path following graduation. Note: U-Female $=$ University female; U-Male = University male; CC-Female = Community College Female; CC-Male = Community College Male. * Indicates differences between male and female responses, using a 2 proportions Z-test $(p \leq 0.05)+$ Indicates differences between university and community college responses, using a 2 proportions Z-test $(p \leq 0.05)$.

\section{Discussion}

Overall, we found that young adults enrolled in collegiate agricultural programs seem to be concerned about agricultural health and safety. Targeting this population for health and safety trainings may be advantageous. One benefit of these trainings is that they may foster communication between students and other agriculturalists, since $72 \%$ of participants reported their concern about the health and safety of their family members, co-workers, and peers in agriculture. These discussions could also extend to students and their healthcare providers, as only one-third of all participants in this study reported discussing agricultural health and safety issues with their health care provider.

There were statistically significant differences noted between education type and gender with reported career path. Higher proportions of male participants reported returning to their family-owned farms, whereas female participants were more likely to report working in an agricultural business or cooperative. Despite these differences, all participants described future careers with potential to impact agricultural health and safety. 
For example, individuals working at an agribusiness or for an agricultural cooperative may make management decisions that could affect employees' health and safety. Likewise, careers in consulting, agricultural education, or government work are also likely to impact the health and safety of farmers. Following the program, we interviewed one female student in Iowa who was pursuing agribusiness and marketing, rather than working on a family farm. She stated, "I believe that many students in our class will take several of these topics with us as we continue our journey within the agricultural industry." This suggests that students perceive opportunities to integrate health and safety into a variety of agricultural settings.

There were also some statistically significant differences among reported safety behaviors based on participant education type and gender. University participants were more likely to wear hearing protection and eye safety devices, females were more likely to wear sunscreen, and males reported being in more "near-miss" and crash events while operating agricultural machinery on roadways. There were also differences among common agricultural tasks performed between education types and gender. It is important to identify these demographic differences in safety behaviors to tailor educational programming to fit the needs of different audiences. For example, topics related to welding and safe grain handling may be better targeted during trainings with community college males, whereas livestock handling safety (including issues related to poultry handling) may be a better fit for female participants. Additionally, because males were more likely to be involved in a "near-miss" or crash event, trainings involving a high proportion of male students could discuss roadway safety in more depth.

It was encouraging that many young adults in agriculture reported "sometimes" using sunscreen, since previous studies have observed low rates of sunscreen use among farmers. In a study of more than ten thousand individuals in the U.S., approximately one third of all participants were "very likely" to wear sunscreen [23], which is significantly more than the young adults in this study who would "always" wear it. However, when comparing young adults' sunscreen habits specifically to those of older farmers, the young adults fared much better. In a previous study, only $7 \%$ of older farmers reported they "always" or "most of the time" wear sunscreen compared to $10.3 \%$ of the young adults in this study who "always" wear it [24]. Exactly half of the older farmers reported "never" wearing sunscreen as compared to only approximately one-quarter of young adults in this study who reported "never" wearing sunscreen in this study [22]. Similar to this study's results, the researchers of the white U.S. population found that females were more likely to wear sunscreen than males [23]. AHSA educational staff has also noted in trainings that female participants are significantly more likely to show interest in training incentives related to sun-safety used during the training, such as sun-safe work hats. This study shows promise that young adults in agriculture currently use and will continue to use sunscreen more regularly than older agricultural workers. We recognize that young females in agriculture may have a strong influence when it comes to adopting more sun-safe practices.

Fewer previous studies have examined reported hearing protection device and eye safety usage by farmers. A study examining PPE use among all farmers in the Midwestern U.S. found that only $7 \%$ of older farmers reported "always" or "most of the time" wearing hearing protection in noisy environments [24]. In comparison, we found that $14 \%$ of young adults reported "always" wearing hearing protection. Larger proportions of older farmers reported "never" or "rarely" wearing ear protection in the form of earmuffs or earplugs ( $78 \%$ and $72 \%$, respectively) [25]. In comparison, only $19 \%$ of participants in this study reported "never" wearing hearing protection. The same study found that $<10 \%$ of older farmers reported wearing safety glasses "most of the time" when performing tasks such as chainsaw and metalworking, and over $50 \%$ stated that they "never" wore safety glasses when performing such tasks [24]. In comparison, 30\% of young adults in this study reported "always" wearing eye protection and only 13\% reported "never" wearing safety glasses in similar situations. Like sunscreen use, the young adults in agriculture studied 
in this research show increased usage of hearing protection devices and eye protection as compared to older farmers.

To our knowledge, this was the first study to ask young adults in agriculture to selfreport their "near-miss" and crash statistics while operating farm equipment on roadways. A recent study found there were more than 7000 reported crashes involving farm equipment in the upper Midwest region [26] in a five-year period. However, the number of "nearmisses" involving farm equipment and other vehicles on the roadway remains unknown. This study provides baseline data for comparison purposes in future studies. We found that higher proportions of college males reported being in "near-misses" or crashes $(12 \%$ and $11 \%$, respectively). Although these proportions seem small, it is important to encourage the safe operation of farm equipment on roadways among the young agricultural population since the effects of such an incident can be devastating, financially and physically [27]. It is interesting that reported numbers of "near-misses" and crashes in this study were similar, as we expected the rates of "near-misses" to be much higher than actual crashes. A photo of a "near-miss" event was included in the survey question prompt, so it is not anticipated that the issue was because of question wording. This may have been the result of recall bias since crashes often are more severe and result in more damage [26]. While this study did not assess injury occurrence or severity in the reported crashes, these statistics would be critical in the long-term measurement of the training effectiveness. Young adults are particularly susceptible to vehicular roadway crashes overall, so it is helpful to use the approach of safe farm equipment operation on the roadways to raise overall roadway safety awareness in this population.

There were some limitations to the analysis of the self-report data. Self-report data could be considered an unfavorable method of data collection when compared to direct observation because it may be impacted by social desirability bias. Social desirability bias may occur when participants respond in more socially desirable ways (the way they think the researchers want them to respond) instead of responding in ways that are reflective of their true feelings or behaviors [28]. Because participants were aware that this training focused on agricultural health and safety, they may have responded in more socially desirable ways, like stating that they wear sunscreen and hearing protection devices more often. They may also be more likely to report the positive impact of the training on the post-survey. We acknowledge that the post-survey data was slightly skewed due to the lower response rate on the post-survey $(N=201)$ compared to the presurvey $(N=790)$. The proportions of certain demographic characteristics of respondents in the pre-survey and post-survey were dissimilar; a significantly higher proportion of females and university participants chose to answer the post-survey compared to males and community college participants. We acknowledge that the use of only three measures (always/sometimes/never) to determine the frequency of studied safety behaviors is not ideal. However, the three measures allowed for analysis of overall trends, which was the purpose of this study.

The training seemed to be impactful on young adults in agriculture pursuing collegiate education. After the program, young adult participants reported that they were more aware of agricultural health and safety issues. They were also more likely to engage in discussions about agricultural health and safety topics with their family members, coworkers, and peers following the program. Participants seemed to positively change their safety behaviors, as they reported that they would use hearing protection and eye safety devices more often. Sixteen and thirty percent of participants reported that they had purchased additional hearing protection and eye safety devices following the training, respectively. One male student from Iowa stated, "Before this training, I didn't think much of wearing hearing protection. Once I saw all the noise levels related to farm work in this training, I think I need to go out and get some." A female student from Minnesota stated that she was likely to download a "noise-meter" app for her cell phone immediately following the training. Several participants indicated that they were interested in purchasing hearing protection devices with Bluetooth capability, so that they could perform agricultural work 
while listening to music or podcasts at safe noise levels. Several male participants enrolled in community colleges reported that eye protection (e.g., safety glasses) were a frequent requirement in their shop classes.

\section{Conclusions}

Young adults in collegiate agricultural programs are a critical audience for agricultural health and safety training. The Gear Up for Ag Health and Safety ${ }^{\mathrm{TM}}$ training program utilizes evidence-based information to educate college-aged populations about agricultural health and safety. This is important, since we found that most participants intend to work on a family-owned agricultural operation or for an agribusiness/cooperative following graduation. These pre- and post-survey techniques provided valuable insights which will continue to inform future approaches to trainings. For example, future agricultural health and safety trainings should be uniquely tailored, accounting for differences in gender and education.

Demographic differences were analyzed for participants' self-reported safety behaviors, including sunscreen use, eye safety use, hearing protection device use, and "near-miss" and crash statistics. Although there were limitations, the study was promising in that higher proportions of young adults in agriculture were reporting safety related behaviors when compared to older adults in the same industry. This may indicate an important, preliminary shift in culture when it comes to thinking about safety. After the training, participants shared their awareness of agricultural health and safety, their willingness to share the information they learned, and their intention to change safety behaviors. The results of this study have shown that that trainings like this are effective and that the young adult population will continue to be an important population, since they will be the next generation of agricultural workers.

Author Contributions: J.L.G., Conceptualization, Methodology, Formal Analysis, Writing-Original Draft Preparation, Project Administration; K.W., Methodology, Formal Analysis, Writing-Original Draft Preparation, Writing-Review and Editing; C.E.S., Conceptualization, Methodology, Software, Supervision, Writing - Review and Editing; M.C., Conceptualization, Methodology, Software, D.S.; Writing - Original Draft Preparation, Methodology; B.J., Conceptualization, Writing—Review and Editing, Methodology, Funding Acquisition, Supervision; D.S.R., Conceptualization, WritingReview and Editing, Methodology, Funding Acquisition, Supervision. All authors have read and agreed to the published version of the manuscript.

Funding: This research was supported in part by Grant Number 5 U54 OH007548 from CDCNIOSH. Survey question design was supported in part by the Central States Center for Agricultural Safety and Health at the University of Nebraska Medical Center. Survey question analysis, study concept and design were supported by the Great Plains Center for Agricultural Health at the University of Iowa. The contents of this article are the responsibility of the authors and do not necessarily represent the official views of the CDC or NIOSH.

Institutional Review Board Statement: The University of Iowa IRB reviewed this project in June 2020 and determined the project did not meet the regulatory definition of human subjects, since no identifying information was collected and it was an evaluation of community education programs for a specific setting. The survey data is collected for the ongoing evaluation and improvement process of the Gear $\mathrm{Up}$ for $\mathrm{Ag}^{\mathrm{TM}}$ as an outreach program and is not generalizable to individuals outside of the program. IRB Ref: 202006249.

Informed Consent Statement: Not applicable.

Data Availability Statement: Not applicable.

Acknowledgments: The authors would like to thank Skylar Rinker at Iowa State University for his support for tailoring this training uniquely to the agricultural education needs of young adults. They would like to thank Risto Rautiainen at the University of Nebraska Medical Center for his influence on survey question design. In addition, the authors would like to thank Jared Wilkens for his assistance with managing the survey database. 
Conflicts of Interest: Authors K.W., J.L.G., D.S., and C.E.S. perform work for the Ag Health and Safety Alliance ${ }^{\mathrm{TM}}$, a 501(c)(3) non-profit organization in the U.S. and Canada that focuses on health and safety for the next generation of agriculture through the delivery of the Gear Up for Ag Health and Safety ${ }^{\mathrm{TM}}$ program. This $2-5 \mathrm{~h}$ program targets students enrolled in agricultural production programs in the collegiate environment and operates through established partnerships with host institutions. The grant funding for this research was used for solely for the evaluation of this ongoing community education program. Authors K.W., J.L.G., D.S., and C.E.S. acknowledge that the research findings from the Gear Up for $\mathrm{Ag}^{\mathrm{TM}}$ training program is intended to serve as an example for other similar health and safety training programs—and that these findings are not intended to solely to benefit the Gear Up for $\mathrm{Ag}^{\mathrm{TM}}$ training program. The authors believe the findings from this example may be applicable to multiple other programs.

\section{References}

1. National Institute for Occupational Safety and Health (NIOSH). Workplace Safety and Health Topics: Agricultural Safety. Available online: https:/ / www.cdc.gov/niosh/topics/aginjury/default.html (accessed on 30 November 2020).

2. Occupational Safety and Health Administration (OSHA). Summary: Youth in Agriculture. Available online: https://www.osha. gov/SLTC/youth/agriculture/ (accessed on 30 November 2020).

3. Adekoya, N.; Pratt, S.G. Fatal Unintentional Farm Injuries in Persons Less than 20 Years of Age in the U.S. National Institute for Occupational Safety and Health (NIOSH). Available online: https://www.cdc.gov/niosh/docs/2001-131/pdfs/2001-131.pdf (accessed on 30 November 2020).

4. McCallum, D.M.; Murphy, S.; Reed, D.B.; Claunch, D.T.; Reynolds, S.J. What we know about the effectiveness of farm safety day programs and what we need to know. J. Rural Health 2013, 29, 20-29. [CrossRef] [PubMed]

5. Hard, D.L. Partnering strategies for Childhood Agricultural safety and Health. J. Agromed. 2012, 17, 225-231. [CrossRef] [PubMed]

6. United States Bureau of Labor Statistics. Employed Persons in Agriculture and Nonagricultural Industries by Age, Sex, and Class of Worker. Available online: https:/ / www.bls.gov/cps/cpsaat15.htm (accessed on 10 December 2020).

7. US Census Bureau. American Community Survey Public Use Microdata Sample (ACS PUMS) from Year 2019. Available online: https:/ / www.census.gov / programs-surveys/acs/microdata/documentation.html (accessed on 2 January 2021).

8. United States Department of Agriculture (USDA) Economic Research Service. Share of Principal Farm Operators with College Degrees has Increased. Available online: https:/ / www.ers.usda.gov/data-products/chart-gallery/gallery/chart-detail/?chartId= 76128 (accessed on 2 January 2021).

9. United States Department of Agriculture (USDA) Economic Research Service. Rural Education Summary. Available online: https: / / www.ers.usda.gov/topics/rural-economy-population/employment-education/rural-education/ (accessed on 30 November 2020).

10. Padhy, C.; Jena, B.K. Effect of agricultural education on farmers efficiency: A review. Int. J. Eng. Technol. Manag. Appl. Sci. 2015, 3, 247-258.

11. Brown, J.P.; Weber, J.G. The Off-Farm Occupations of U.S. Farm Operators and Their Spouses; EIB-117; U.S. Department of Agriculture: Washington, DC, USA, 2013.

12. Adrian, A.M.; Norwood, S.H.; Mask, P.L. Producers' perceptions and attitudes towards precision agriculture technologies. J. Comput. Electron 2005, 48, 256-271. [CrossRef]

13. Daberkow, S.G.; McBride, W.D. Farm and operator characteristics affecting awareness and adoption of precision agriculture technologies in the U.S. Precis. Agric 2003, 4, 163-177. [CrossRef]

14. United States Department of Agriculture (USDA) National Agricultural Statistics Service. 2017 Census of Agriculture. Available online: https: / / www.nass.usda.gov/Publications/AgCensus/2017/index.php\#full_report (accessed on 30 November 2020).

15. Reed, D.B.; Browning, S.R.; Westneat, S.C.; Kidd, P.S. Personal protective equipment use and safety behaviors among farm adolescents: Gender differences and predictors of work practices. J. Rural Health 2006, 22, 314-320. [CrossRef] [PubMed]

16. Zepeda, L.; Kim, J. Farm parents' views on their children's labor on family farms: A focus group study of Wisconsin dairy farmers. Agric. Human Values 2006, 23, 109-121. [CrossRef]

17. Kirkpatrick, D.L.; Kirkpatrick, J.D. Evaluating Training Programs: The Four Levels; Berrett-Koehler: San Francisco, CA, USA, 2006.

18. Centers for Disease Control and Prevention. Public Health EDUCATION and Training Development. Available online: https: //www.cdc.gov/trainingdevelopment/develop-training/addie/training_effectiveness.html (accessed on 5 January 2020).

19. Pennings, J.M.; Irwin, S.H.; Good, D.L. Surveying farmers: A case study. Appl. Econ. Perspect. Policy 2002, 24, 266-277. [CrossRef]

20. Pennings, J.M.; Irwin, S.H.; Good, D.L. Surveying Farmers: A Research Note. SSRN. Available online: http://dx.doi.org/10.213 9/ssrn.244502 (accessed on 5 January 2020).

21. Fleiss, J.L.; Tytun, A.; Ury, H.K. A simple approximation for calculating sample sizes for comparing independent proportions. Biometrics 1980, 36, 343-346. [CrossRef] [PubMed]

22. Cochran, S.D. 2004. Two Sample Z-Tests. UCLA. Available online: http://www.stat.ucla.edu/ \{\}cochran/stat10/winter/ lectures/lect21.html (accessed on 8 December 2020).

23. Hall, H.I.; May, D.S.; Lew, R.A.; Koh, H.K.; Nadel, M. Sun protection behaviors of the U.S. white population. Prev. Med. 1997, 24, 401-407. [CrossRef] [PubMed] 
24. Carpenter, W.S.; Lee, B.C.; Gunderson, P.D.; Stueland, D.T. Assessment of personal protective equipment use among Midwestern farmers. Am. J. Ind. Med. 2002, 42, 236-247. [CrossRef] [PubMed]

25. Griffin, S.C.; Neitzel, R.; Daniell, W.E.; Seixas, N.S. Indicators of hearing protection use: Self-report and researcher observation. J. Occup. Environ. Hyg. 2009, 10, 639-647. [CrossRef] [PubMed]

26. Ramirez, M.; Bedford, R.; Wu, H.; Harland, K.; Cavanaugh, J.E.; Peek-Asa, C. Lighting and marking policies are associated with reduced farm equipment-related crash rates: A policy analysis of nine Midwestern, U.S. states. Occup. Environ. Med. 2016, 73, 621-626. [CrossRef] [PubMed]

27. Raphael, K. Recall bias: A proposal for assessment and control. Int. J. Epidemiol. 1987, 16, 167-170. [CrossRef] [PubMed]

28. Grimm, P. Social Desirability Bias. In Wiley International Encyclopedia of Marketing; Sheth, J., Malhotra, N., Eds.; John Wiley \& Sons: Hoboken, NJ, USA, 2010. 